\title{
Applications of Al-Based Forecasts in Renewable Based Electricity Balancing Markets
}

\author{
Hameed, Zeenat; Hashemi Toghroljerdi, Seyedmostafa; Træholt, Chresten
}

Published in:

Proceedings of 2021 IEEE International Conference on Industrial Technology

Link to article, DOI:

10.1109/ICIT46573.2021.9453469

Publication date:

2021

Document Version

Peer reviewed version

Link back to DTU Orbit

Citation (APA):

Hameed, Z., Hashemi Toghroljerdi, S., \& Træholt, C. (2021). Applications of AI-Based Forecasts in Renewable Based Electricity Balancing Markets. In Proceedings of 2021 IEEE International Conference on Industrial Technology (pp. 579-584). IEEE. https://doi.org/10.1109/ICIT46573.2021.9453469

\section{General rights}

Copyright and moral rights for the publications made accessible in the public portal are retained by the authors and/or other copyright owners and it is a condition of accessing publications that users recognise and abide by the legal requirements associated with these rights.

- Users may download and print one copy of any publication from the public portal for the purpose of private study or research.

- You may not further distribute the material or use it for any profit-making activity or commercial gain

- You may freely distribute the URL identifying the publication in the public portal 


\title{
Applications of AI-Based Forecasts in Renewable Based Electricity Balancing Markets
}

\author{
Zeenat Hameed ${ }^{1}$, Seyedmostafa Hashemi ${ }^{2}$, Chresten Træholt ${ }^{3}$ \\ Department of Electrical Engineering \\ Technical University Denmark \\ Kongens Lyngby, 2800, Denmark \\ zeeha@elektro.dtu.dk ${ }^{1}$, shtog@elektro.dtu.dk ${ }^{2}$, ctr@elektro.dtu.dk ${ }^{3}$
}

\begin{abstract}
Rising environmental concerns are integrating more renewables in power systems. This increase introduces uncertainty in generation and makes it challenging to maintain a balance between demand and supply. To avoid balancing problems and consequent stability issues, better forecast models are needed as traditional techniques are not fully equipped to deal with these new challenges. Thus, artificial intelligence (AI) based forecast techniques are gaining potential recognition in the realm of electricity markets. This paper aims at investigating the state-of-art of AI applications for price forecasts in electricity balancing markets (EBMs). The focus of previous studies extended in this direction has been towards the dayahead markets, whereas studies targeting EBMs are rather scarce. This paper shows how AI-based forecasts support EBMs modeling, resulting in more secure grid integration of distributed technologies. The benefits driven from such forecasts by market participants like brokers and customers are also investigated.
\end{abstract}

Keywords-artificial intelligence, balancing markets, imbalance settlement, forecasts, classification, modeling, brokers

\section{INTRODUCTION}

For the past few decades, the dynamics of electricity markets have been changing. This is mainly due to the rising environmental concerns, which have led to greater renewable energy sources (RES) integration into the system [1]. On the one hand, higher RES has helped power markets achieve cleaner and greener energy portfolios, but on the other hand, their intermittent nature has resulted in greater stability issues [2]. For the maintenance of system stability, keeping a controlled flow of power to maintain a balance between the demand and supply is one of the most important roles of transmission system operators (TSOs). Increasing the RES mix in the power grid introduces uncertainty and variability in the supply and makes the balancing tasks more challenging. To avoid balancing problems and stability issues, better forecast models are needed [3]. Thus, AI and machine learning (ML) techniques, due to their advanced forecasting capabilities are gaining tremendous attention [4], [5].

But so far, studies have mainly been conducted for AIbased estimations in day-ahead markets. From the review literature such as [6]-[8], it can be seen that such studies for the case of balancing markets are rather scarce. Even though in [9], a range of models was benchmarked to forecast balancing market prices, but AI-based methods were not targeted. Currently, as growing volumes of RES generation is increasing system balancing requirements, the studies on changing dynamics of EBMs are becoming more important [10]. Therefore, this paper reviews the state-of-art on the role

This work is supported by the Danish project "BOSS: Bornholm smartgrid secured by grid connected battery systems" co-founded by Danish Energy technology Development and Demonstration program (EUDP) contract no. 64018-0618. of AI-based forecasts in EBMs. It also investigates the applications of AI-based forecasts in balancing markets for system modeling, cost-effective services, customer participation, etc. This is important as [11], [12] highlight that most of the forecasting literature has been directed towards bettering forecast accuracies, whereas, the applications of the results of the forecasts have largely been ignored. Furthermore, this paper also investigates how different players in EBMs like system operators, brokers, and customers can benefit from the applications of AI-based forecasts.

The paper contains six sections. In section II, an overview of pricing mechanisms in EBMs is presented, the impact of high RES penetration on EBMs is discussed and the need for better forecasts in EBMs is established. In section III, key challenges in traditional forecasting techniques are identified. In section IV, the key advantages of AI-based techniques over traditional techniques are explored and the applications of AIbased forecasts in EBMs are investigated. In Section V, the importance of deriving value in the form of trading strategies and risk management plans from AI-based forecasts is discussed. Finally, in section VI, the paper is concluded with a summary and final remarks.

\section{ELECTRICITY BALANCING MARKETS - KEY CONCEPTS AND THE NEED FOR FORECASTS}

A system that enables electricity trade is an electricity market. Depending on the time interval in which the trade occurs its operation can be divided into the bilateral, dayahead, intra-day, and balancing market [13], [14]. Balancing markets take place just minutes before actual energy delivery. They are used to balance the production and consumption, as closely as possible, before it is supplied to the customers [15].

\section{A. Pricing Mechanisms in Electricity Balancing Markets}

The EBMs function under the supervision of TSOs, who receive up and down-regulation bids from different producers depending on the needs of the system [16]. When there is excess demand in the system, the up-regulation bid is activated. This implies that there is a need to increase the production that was originally left out of the day-ahead market. As this increase should occur in a relatively short notice period, hence this production is relatively costlier than the one dispatched in the day-ahead market [17]. This is illustrated in Fig.1. in green color. Here, $\mathrm{P}_{\mathrm{N}} \mathrm{S}$ represents the production scheduled in the day-ahead market. It can be seen that when there is excess demand in the system, a dispatchable generator can offer balancing power $\mathrm{P}_{\mathrm{Bi}}{ }^{\mathrm{Umax}}$ for a price $\lambda_{\mathrm{Bi}}{ }^{\mathrm{U}}$ that is higher than the market-clearing price $\lambda_{\mathrm{s}}$ of day-ahead market. Thus, the generator earns a profit as the following equation holds [17].

$$
\lambda_{\mathrm{Bi}}^{\mathrm{U}} \geq \lambda_{\mathrm{S}}
$$




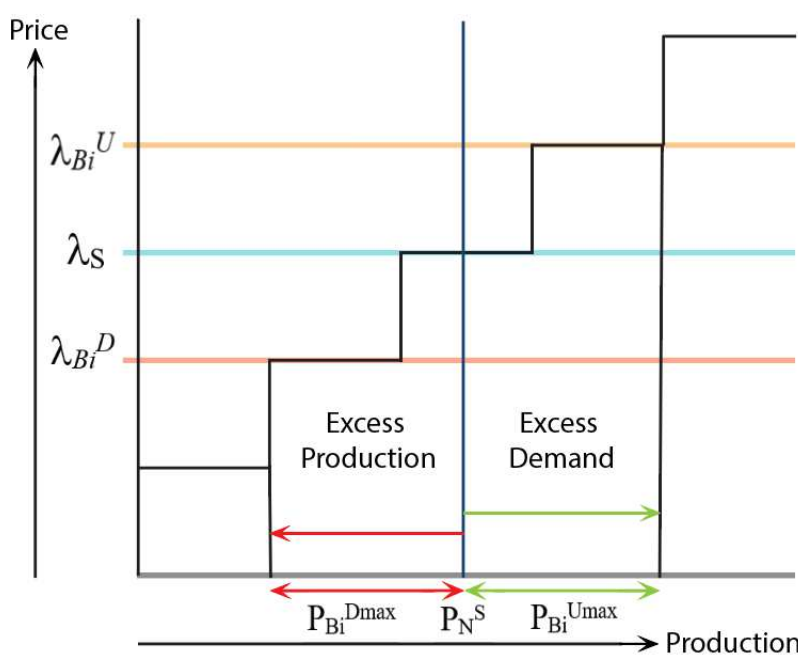

Fig. 1: Pricing Mechanism in Electricity Balancing Markets

On the other hand, when the system has excess production it implies submission of down-regulation bids. This means that the dispatchable generator is willing to repurchase part of its dispatched production. Such a repurchase pays off, only if its price is lesser than what it was in the day-ahead market [17]. This is also represented in Fig.1. in red color. In this case, a generator can offer to repurchase power $\mathrm{P}_{\mathrm{Bi}}{ }^{\text {Dmax }}$ for a price $\lambda_{\mathrm{Bi}}{ }^{\mathrm{D}}$ that is lower than market-clearing price i.e.

$$
\lambda_{\mathrm{Bi}}^{\mathrm{D}} \leq \lambda_{\mathrm{S}}
$$

\section{B. Renewable Integration in Electricity Balancing Markets}

The balancing mechanisms discussed above are straight forward for the case of dispatchable generators such as hydroelectric and gas power plants. On the other hand, stochastic generators, like solar and wind plants, cannot control the level of their production, thus complicating the balancing procedures. Consequently, to handle the complications, different pricing mechanisms exist in EBMs, such as,

- Single-price imbalance settlement

- Two-price imbalance settlement

In single-price imbalance settlement, both the dispatchable and stochastic generators are treated in the same way. Thus, in case of excess demand in the system, the stochastic generator that is producing higher energy than its scheduled value of the day-ahead market can also sell it for a price $\lambda_{B \mathrm{~B}}{ }^{\mathrm{U}}$ and earn a profit. On the other hand, a stochastic generator that has a lower production than scheduled has to purchase energy at a higher price thus experiencing a revenue loss [17].

But in two-price imbalance settlement, imbalances of any kind from the stochastic generators are not incentivized. Therefore, when there is excess demand in the system, and the stochastic generator has higher production than scheduled, it is paid with the day-ahead market clearing price $\lambda_{S}$ and not the higher price $\lambda_{\mathrm{Bi}} \mathrm{U}$. In the case of excess production in the system, the stochastic generator with lower generation than scheduled, repurchases with the price $\lambda_{s}$ and not a lower price $\lambda_{\mathrm{Bi}}{ }^{\mathrm{D}}$, thus experiencing a revenue loss [17]. In this case, the stochastic generator with higher production than scheduled experiences an opportunity loss because it has to sell at a lower

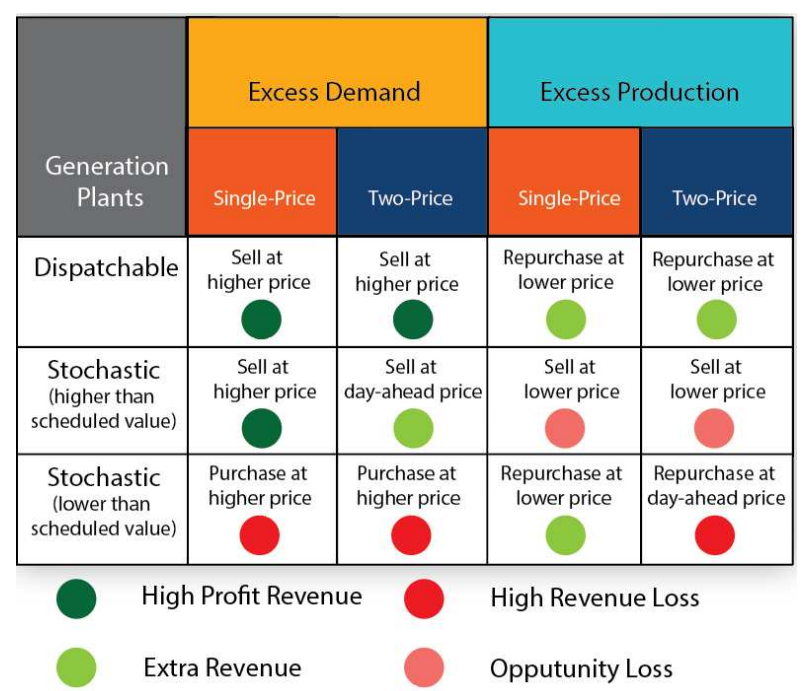

Fig. 2: Summary of Benefits/Losses in Single-Price and Two-Price Imbalance Settlement Schemes

market price $\lambda_{\mathrm{Bi}}{ }^{\mathrm{D}}$. A summary of the participation of stochastic and dispatchable generators in both types of settlements is presented in Fig.2. The value of transactions in the form of profit, extra revenue, loss, and opportunity loss is also highlighted in Fig.2.

\section{Importance of Forecasts in Electricity Balancing Market}

From the above discussion, it is clear that output power forecasts are of paramount importance for RES generators. It is due to discrepancies in their forecasted and real values that imbalances exist in the system, which in many cases lead to revenue and opportunity losses for RES owners [18]-[20].

Furthermore, these imbalances also put other market participants such as dispatchable plant owners, brokers, etc. under higher uncertainty. This is because larger RES penetration introduces higher price fluctuations in markets which makes it challenging for the participants to decide whether they should trade in the day-ahead market or the balancing market. This causes a negative impact on their trading strategies which effects market prices. Consequently, customers end up paying higher electricity bills.

Therefore, for the smooth functioning of electricity markets, better models to incorporate RES power forecasts are needed. Additionally, careful considerations on EBMs pricing mechanisms are required [10]. But as electricity prices show higher volatility as compared to other commodities they are harder to predict [21]. Key challenges in using traditional forecast techniques are presented in the next section.

\section{Key Challenges in TRAditional Forecast Methods}

Four types of forecasting methods have mainly been used for forecasting in electricity markets, namely, persistence methods, physical methods, statistical methods, and AI-based methods. They are represented in Fig.3.

When persistence methods are used, future observations are considered to have the same values as those of current instances. Due to the simplicity and naivety of these methods, they have limited applications in decision-making processes in EBMs and are usually used only to test the forecast accuracy of other methods [22], [23]. Physical methods on the other hand require complex mathematical modelling of 


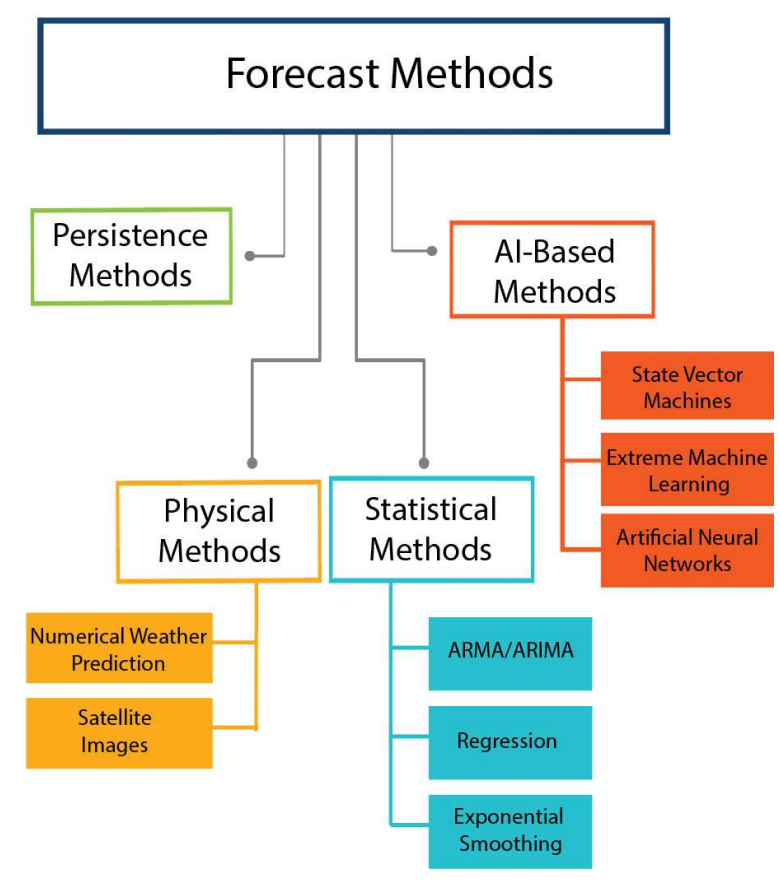

Fig. 3: Forecast Methods in Electricity Markets

environments in which variables of interest are being governed. For example, in the case of electricity markets, if price prediction is desired, it would imply devising a complex model of market rules and market players' behaviours [24].

In statistical methods, models are devised using principles of statistics, and inferences are drawn from historical observations [25]. Using these methods in EBMs does not give accurate results as many influential factors such as load, generation price, and fuel cost, etc. are neglected [26].

Statistical methods using autoregressive techniques deploy simple linear forecasters which prevent them from capturing the non-linearities of the system. For example, in [27] the statistical price model did not explicitly consider the market structure and used scenario trees for generating a large number of representative market scenarios. But such representations are not always possible or desired.

\section{Key APPLICATIONS OF AI-BASED ForeCASt METHODS}

AI-based methods present higher accuracy and fulfil better computational requirements in terms of performance as compared to traditional methods. For example, in artificial neural networks (ANN), trend and pattern detection are easier than statistical models. They also present better capability in handling classification, clustering, estimation, recognition etc. They can also handle non-linear dependencies, a feature which is not possible in statistical or physical methods [28], [29]. Therefore, in [30]-[32] AI-based methods are presented as a solution to forecasting problems in electricity markets.

Some shortcomings exist in AI models as well. For example, from [8], it can be seen that when neural network and fuzzy logic models were used in electricity markets' forecasts they experienced generalization problems and proved to be unsuitable for unseen data. But fortunately, other AI-based approaches such as support vector machines (SVMs), can help in such cases by reducing the model complexities. In [8], [31] a smaller training data for price forecasts using SVM helped to resolve the drawbacks of

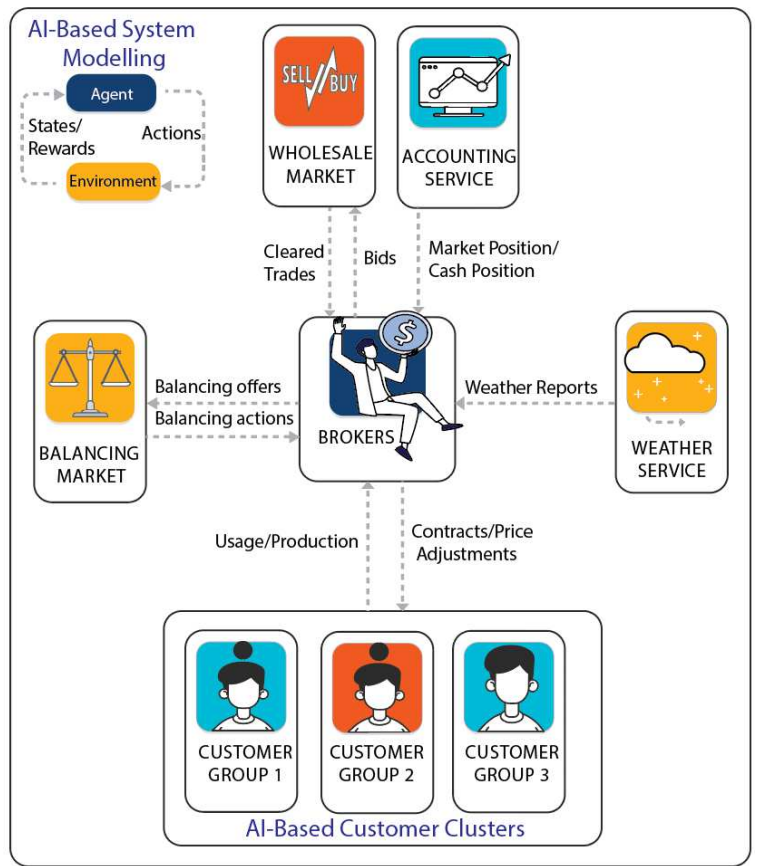

Fig. 4: AI-based Market System Modelling

neural networks. In this section, applications of AI-based methods in EBMs are investigated for different roles.

\section{A. AI-Based Market System Simulation}

As balancing markets involve complex interactions between numerous participants, therefore simulation of EBMs as multi-agent models play a crucial role in understanding market dynamics. Such understandings help in evaluating the economic impact of systematic imbalances as seen in [33].

In the literature, an AI-driven reinforcement learningbased platform known as power trading agent competition (PowerTAC) has been repeatedly used for EBM system simulation [34]. It simulates the EBMs structure, which is tuned after each simulation step according to the changing market demands. It incorporates RES output forecasts, weather forecasts, and price forecasts for regulating agent's behavior patterns. This technique has been used in [35]-[37], where pricing methodologies and trading strategies have been developed for brokers involved in EBM transactions.

AI-based techniques also help brokers in clustering customers into different groups based on their needs. In [35] such groupings helped brokers in formulating a variety of pricing mechanisms to satisfy the varying requirement of different clusters of customers. It also helped them in earning higher rewards by outperforming those brokers who used predetermined or randomized strategies.

In Fig.4. The AI-based EBM system model is illustrated. The agent is a broker who learns from the environment, which includes several entities such as balancing market, customers, weather services, and wholesale market. Based on the learned inputs from the environment, the broker makes decisions on balancing offers, price adjustments, and market bids. In Fig.4. AI-based clustering of customers is also illustrated.

Furthermore, such AI-based system models also help market players in predicting competitors' responses. In [38] multiple market scenarios were generated to help the market participants in predicting the competitor's actions. Thus, AIbased methods find extensive use in modeling EBMs. They 


\begin{tabular}{|c|c|c|c|c|}
\hline \multicolumn{2}{|c|}{ FORECAST VALUE } & MARKET & BROKERS & CUSTOMERS \\
\hline Al-based Market System Simulation & & $\begin{array}{c}\text { System balance } \\
{[33],[35]-[38]}\end{array}$ & $\begin{array}{c}\text { Effective trade } \\
{[35]-[38]}\end{array}$ & $\begin{array}{c}\text { Pricing variety } \\
{[35]}\end{array}$ \\
\hline Al-based Market Price Classification & & $\begin{array}{c}\text { System balance } \\
{[21],[39],[40]}\end{array}$ & $\begin{array}{c}\text { Grid integration } \\
{[21]}\end{array}$ \\
\hline Al-based Imbalance Capacity Prediction & - & $\begin{array}{c}\text { System balance } \\
{[41]-[42]}\end{array}$ & $\begin{array}{c}\text { Effective trade } \\
{[41]}\end{array}$ & $\begin{array}{c}\text { Lower bills } \\
{[42]}\end{array}$ \\
\hline Al-based Demand Side Management & - & $\begin{array}{c}\text { System balance } \\
{[46],[47]}\end{array}$ & $\begin{array}{c}\text { Lower bills } \\
{[47]}\end{array}$ \\
\hline Al-based Distributed Technologies Integration & - & $\begin{array}{c}\text { System balance } \\
{[48],[49]}\end{array}$ & $\begin{array}{c}\text { Grid integration } \\
{[50]}\end{array}$ \\
\hline
\end{tabular}

Fig. 5: Qualitative Summary of Stakeholder Benefit from AI Applications in Electricity Balancing Markets

help market players in developing profit-maximizing trading strategies. Such system simulations are not possible if physical methods are used instead of AI-based methods as they are characterized by high computational complexity which hinders their use in short-term predictions.

\section{B. AI-Based Market Price Classification}

Nowadays in smart grids, the consumers with locally installed RES can gain monetary benefits by signing up their resources for balancing services. For promoting such behaviours, classification of electricity prices is important because usually the customers are not well-equipped with the knowledge of electricity markets and all they are concerned with are the price thresholds instead of price values.

$\mathrm{AI}$ technologies such as state vector machines (SVM) are well equipped to perform clustering and classification tasks on high-dimensional data sets. In [21], an AI-based extreme machine learning approach was developed for presenting price thresholds to customers which gave them adequate price statuses for making informed and timely decisions. Such classifications also find applications in incorporating virtual power plants (VPPs) into EBMs. VPPs use demand response (DR) and distributed generation (DG) units which are relatively small in size, and hence have to be clustered together to manage the required amount of reserve capacity [39]. In [40], when DGs and DRs were clustered using AI techniques, to provide distributed balancing services, they responded to predicted load and price signals and accordingly altered their operation.

\section{AI-Based Imbalance Capacity Prediction}

Capturing complex market system dynamics is important for the procurement of balancing capacity in EBMs. This is because if static approaches are used, they imply maintenance of a constant reserve for a certain period which puts customers under extra costs of unused capacity.

On the other hand, in [42], when using AI-based dynamic approach different reserve capacities for every quarter-hour were proposed depending on the RES forecasts, load forecasts, their gradients, calendar, and time effects. It led to lower balancing costs. Thus AI-based techniques can accommodate changing market behaviors and produce accurate and realistic predictions.

This would have not been possible if statistical approaches were used instead. For example, in [43], when the statistical method approach was used, only regulating volumes were considered to estimate regulating prices and other system dynamics were ignored. Similarly, in [44], the statistical methods were not able make accurate price predictions but instead only generated signals, to direct whether the energy should be sold in the balancing market, or traded in day-ahead market. On the other hand, in [41], improved predictions of the system imbalance based on deep-learning model were developed to incorporate uncertainty into decision procedure.

\section{AI-Based Demand Side Management}

Nowadays, as customers are also being able to actively interact with market players, new pricing schemes are gaining importance. One such example is dynamic pricing, which presents a choice to customers to be exposed to time-varying electricity prices and hence reduce the burden on EBMs during peak hours [45]. But such dynamic pricing schemes have certain challenges because when customers are free to choose between different utility companies, the companies have to consider the pricing possibilities of other utility companies along with the customer demands. Therefore, in [46], when AI-based machine learning methods were used for price estimation, the utility company achieved high profits.

Furthermore, such AI-based pricing techniques also find applications in allowing customers who do not have local RES generators to participate in the balancing markets. This happens by enabling them to regulate their peak demands by forecasting high prices in advance. This helps them in escaping imbalance penalties, which they receive in the form of high electricity bills. Sometimes, such customer participation can be challenging, as it implies incorporating hundreds of customers in the markets through individual contracts. A solution to this problem was presented in [47], where AI-based neural network techniques were used to jointly optimize customer's demands. In this way, they were able to collectively participate in maintaining system balance.

\section{E. AI-Based Distributed Technologies Integration}

Nowadays, electric vehicles (EVs) are gaining increasing importance in balancing markets. In [48], [49], by using the historical data available for a fleet of EVs, the price and location of the best-suited ones for absorbing or providing electricity during excess or shortage were determined. Thus, signifying the importance of AI-based forecasts in EBMs. As grid fluctuations cannot be compensated by only one or few EVs, AI-based classification techniques have to be used for developing pooling strategies and modelling behaviour patterns of multiple EVs at a time. This was done in [50] where AI-based classifications helped the prosumers in grid integration of their EVs to participate in system balancing.

For all the AI-based forecasts discussed in this section, Fig.5 illustrates, how these applications can benefit the balancing market as well as different participants of the market such as brokers and customers. From the figure, it can 
be seen AI-based market system simulation helps the EBM in maintaining a system balance while helping the brokers in devising effective trading strategies. It also helps customers by presenting them with a variety of pricing mechanisms based on their needs. Hence the circle represents a colour for the beneficiaries, which are all three in this case.

\section{Deriving VAlue From AI-BAsed Forecasts}

In the previous section, the role of AI-based forecasts in EBMs was investigated. It was seen that AI techniques can not only give more accurate power and price forecasts as compared to the traditional techniques but also use those forecasts for other applications such as modeling, classification, and clustering. These AI applications are important because a precise estimation is worthless if it cannot be utilized [51]-[54]. The incremental economic or other benefit realized by decision-makers through the use of forecasts has been recognized as one of the key features of a good forecast [55]. In other words, once certain predictions are made, it is important to use those predictions in a meaningful way to achieve the desired results. Therefore, decisions based on forecasting scheme and analysed for their monetary effects are crucial to derive value from forecasts.

This is usually done in EBMs by devising optimal trading strategies. From [56], [57], it can be inferred that these strategies do not necessarily have to be elaborate or complex; even the simpler ones can produce substantial economic gains when combined with strong AI-based forecasting techniques. Furthermore, as there is usually a high discrepancy in the data on which these forecasts are based, there are some inevitable errors associated with them. For example, uncertainties in weather data cannot be precisely estimated.

Consequently, the characterization of the uncertainty included in such forecasts is of paramount importance. Therefore, operational solutions have to be developed for helping end-users, utilities, TSOs, etc. to better their decisions based on those forecasts. It is important because even if the levels of forecast error might appear acceptable to the user, there can be noteworthy risks associated with them. Therefore, uncertainty estimates should be integrated into the decisionmaking process, for optimizing benefits gained from forecast predictions. This would help in quantifying the economic impacts of imperfect forecasts. Such quantifications can help the market participants design risk management strategies.

\section{CONCLUSIONS}

In this paper, we investigated AI-based electricity market models for simulating actions of EBM participants from their price, power, and load forecasts. AI is playing a significant role in meeting changing demands of balancing markets, and with the higher renewable integration, the applications of AI in balancing markets will continue to increase. We recognized the importance of deriving value from price forecasts in helping market players devise risk management plans and quantifying the economic impact of AI-based forecasts. Furthermore, by investigating the benefits gained by different market players from AI-based forecasts, we identified key areas where customers and brokers can gain financial advantages. We found that AI-based demand-side management, dynamic pricing, and grid integration of RES, motivated customers in active participation in EBMs for reducing their electricity bills. Also, by investigating the classification and clustering capabilities of AI-based approaches such as SVMs, we presented how AI applications enabled aggregation of larger customer data sets; a task that was tedious to accomplish when statistical approaches were used. We concluded that reinforcement learning based platforms present advanced modeling capabilities and are preferred over traditional techniques as the latter involves incorporating complex environmental variables.

\section{REFERENCES}

[1] IRENA, Global energy transformation: A roadmap to 2050 (2019 edition). 2019.

[2] A. Luna, U. Tamrakar, T. M. Hansen, and R. Tonkoski, "Frequency Response in Grids with High Penetration of Renewable Energy Sources," 2018 North Am. Power Symp. NAPS 2018, 2019, doi: 10.1109/NAPS.2018.8600620.

[3] The Danish Energy Agency, "The Danish perspective on forecasting and integration of renewables in power systems," Danish Minist. Clim. Util., no. August, 2020, [Online]. Available: https://ens.dk/sites/ens.dk/files/Globalcooperation/fact_sheet_forecast ing.pdf.

[4] D. Assouline, N. Mohajeri, and J. L. Scartezzini, Estimation of largescale solar rooftop PV potential for smart grid integration: A methodological review, vol. 145. 2018.

[5] R. Ahmed, V. Sreeram, Y. Mishra, and M. D. Arif, “A review and evaluation of the state-of-the-art in PV solar power forecasting: Techniques and optimization," Renew. Sustain. Energy Rev., vol. 124, no. February, p. 109792, 2020, doi: 10.1016/j.rser.2020.109792.

[6] S. Chakravarty, P. Mohapatra, and P. K. Dash, "Evolutionary extreme learning machine for energy price forecasting," Int. J. KnowledgeBased Intell. Eng. Syst., vol. 20, no. 2, pp. 75-96, 2016, doi: 10.3233/KES-160331.

[7] L. Xie and H. Zheng, "Electricity price forecasting by clustering-least squares support vector machine," in Proceedings of the 2013 6th International Congress on Image and Signal Processing, CISP 2013, 2013, vol. 3, pp. 1357-1361, doi: 10.1109/CISP.2013.6743884

[8] I. A. B. W. A. Razak et al., "Support vector machine for day ahead electricity price forecasting," in AIP Conference Proceedings, May 2015, vol. 1660, doi: 10.1063/1.4915865.

[9] G. Klæboe, A. L. Eriksrud, and S. E. Fleten, "Benchmarking time series based forecasting models for electricity balancing market prices," Energy Syst., vol. 6, no. 1, pp. 43-61, 2013, doi: 10.1007/s12667-013-0103-3.

[10] ENTSO-E, "Developing balancing systems to facilitate the achievement of renewable energy goals," no. November, 2011, [Online]. Available: https://www.entsoe.eu/fileadmin/user_upload/_library/position_paper s/111104_RESBalancing_final.pdf.

[11] E. V. Mc Garrigle and P. G. Leahy, "Quantifying the value of improved wind energy forecasts in a pool-based electricity market," Renew. Energy, vol. 80, pp. 517-524, 2015, doi: 10.1016/j.renene.2015.02.023.

[12] N. Mazzi and P. Pinson, "Wind power in electricity markets and the value of forecasting," Renew. Energy Forecast. From Model. to Appl., no. 2007, pp. 259-278, 2017, doi: 10.1016/B978-0-08-100504$0.00010-\mathrm{X}$.

[13] "Power markets." https://www.wind-energy-the-facts.org/powermarkets.html (accessed Aug. 22, 2020).

[14] E. Kiener, “Analysis of Balancing Markets," no. August, 2006.

[15] NordREG Nordic Energy Regulators, "Harmonising the balancing market Issues to be considered," p. 40, 2010, [Online]. Available: www.nordicenergyregulators.org.

[16] "Market." https://www.entsoe.eu/about/market/ (accessed Sep. 06, 2020).

[17] J. M. Morales, A. J. Conejo, H. Madsen, P. Pinson, and M. Zugno, Integrating renewables in electricity markets - Operational problems, vol. 205. 2014.

[18] A. Helander, H. Holttinen, and J. Paatero, "Impact of wind power on the power system imbalances in Finland," IET Renew. Power Gener., vol. 4, no. 1, pp. 75-84, 2010, doi: 10.1049/iet-rpg.2008.0093.

[19] K. Janda, J. Málek, and L. Rečka, "Influence of renewable energy sources on transmission networks in Central Europe," Energy Policy, vol. 108, no. June 2017, pp. 524-537, 2017, doi: 10.1016/j.enpol.2017.06.021. 
[20] M. Mulholland, D. B. Hibbert, P. R. Haddad, and P. Parslov, "A comparison of classification in artificial intelligence, induction versus a self-organising neural networks," Chemom. Intell. Lab. Syst., vol. 30, no. 1, pp. 117-128, 1995, doi: 10.1016/0169-7439(95)00050-X.

[21] R. Bisoi, P. K. Dash, and P. P. Das, "Short-term electricity price forecasting and classification in smart grids using optimized multikernel extreme learning machine," Neural Comput. Appl., vol. 32, no. 5, pp. 1457-1480, 2020, doi: 10.1007/s00521-018-3652-5.

[22] R. H. Inman, H. T. C. Pedro, and C. F. M. Coimbra, "Solar forecasting methods for renewable energy integration," Prog. Energy Combust. Sci., vol. 39, no. 6, pp. 535-576, 2013, doi: 10.1016/j.pecs.2013.06.002.

[23] C. Croonenbroeck and G. Stadtmann, "Renewable generation forecast studies - Review and good practice guidance," Renew. Sustain. Energy Rev., vol. 108, no. April, pp. 312-322, 2019, doi: 10.1016/j.rser.2019.03.029.

[24] B. Luo and S. Miao, "A Literature Survey on Electricity Price Forecasting in Deregulated Markets," in iSPEC 2019 - 2019 IEEE Sustainable Power and Energy Conference: Grid Modernization for Energy Revolution, Proceedings, Nov. 2019, pp. 359-365, doi: 10.1109/iSPEC48194.2019.8974939.

[25] S. K. Aggarwal, L. M. Saini, and A. Kumar, "Short term price forecasting in deregulated electricity markets: A review of statistical models and key issues," Int. J. Energy Sect. Manag., vol. 3, no. 4, pp. 333-358, 2009, doi: 10.1108/17506220911005731.

[26] Z. Cai et al., "Application of battery storage for compensation of forecast errors of wind power generation in 2050," Energy Procedia, vol. 73, pp. 208-217, 2015, doi: 10.1016/j.egypro.2015.07.673.

[27] M. Olsson and L. Söder, "Modeling real-time balancing power market prices using combined SARIMA and Markov processes," IEEE Trans. Power Syst., vol. 23, no. 2, pp. 443-450, 2008, doi: 10.1109/TPWRS.2008.920046.

[28] M. N. Akhter, S. Mekhilef, H. Mokhlis, and N. M. Shah, "Review on forecasting of photovoltaic power generation based on machine learning and metaheuristic techniques," IET Renew. Power Gener., vol. 13, no. 7, pp. 1009-1023, 2019, doi: 10.1049/iet-rpg.2018.5649.

[29] Q. Wang, F. Li, Y. Tang, and Y. Xu, "Integrating Model-Driven and Data-Driven Methods for Power System Frequency Stability Assessment and Control," IEEE Trans. Power Syst., vol. 34, no. 6, pp. 4557-4568, Nov. 2019, doi: 10.1109/TPWRS.2019.2919522.

[30] P. S. Georgilakis, "Artificial intelligence solution to electricity price forecasting problem," Appl. Artif. Intell., vol. 21, no. 8, pp. 707-727, 2007, doi: 10.1080/08839510701526533.

[31] M. Negnevitsky, P. Mandal, and A. K. Srivastava, "Machine learning applications for load, price and wind power prediction in power systems," 2009 15th Int. Conf. Intell. Syst. Appl. to Power Syst. ISAP '09, 2009, doi: 10.1109/ISAP.2009.5352820.

[32] J. E. C. Tee, T. T. Teo, T. Logenthiran, W. L. Woo, and K. Abidi, "Dayahead forecasting of wholesale electricity pricing using extreme learning machine," IEEE Reg. 10 Annu. Int. Conf. Proceedings/TENCON, vol. 2017-Decem, pp. 2973-2977, 2017, doi: 10.1109/TENCON.2017.8228371.

[33] M. Ansarin, W. Ketter, and J. Collins, "Analyzing and improving the energy balancing market in the power trading agent competition," IEEE PES Innov. Smart Grid Technol. Conf. Eur., pp. 1-6, 2016, doi: 10.1109/ISGTEurope.2016.7856197.

[34] “Home | PowerTAC.” https://powertac.org/ (accessed Oct. 15, 2020).

[35] M. De Weerdt, W. Ketter, and J. Collins, "Pricing mechanism for realtime balancing in regional electricity markets," Belgian/Netherlands Artif. Intell. Conf., 2011.

[36] P. P. Reddy, "Learned behaviors of multiple autonomous agents in smart grid markets," Proc. Natl. Conf. Artif. Intell., vol. 2, 2011.

[37] X. Wang, M. Zhang, F. Ren, and T. Ito, "GongBroker: A broker model for power trading in smart grid markets," Proc. - 2015 IEEE/WIC/ACM Int. Jt. Conf. Web Intell. Intell. Agent Technol. WIIAT 2015, vol. 2, pp. 21-24, 2016, doi: 10.1109/WI-IAT.2015.108.

[38] G. Santos, T. Pinto, Z. Vale, H. Morais, and I. Praca, "Balancing market integration in MASCEM electricity market simulator," IEEE
Power Energy Soc. Gen. Meet., pp. 1-8, 2012, doi: 10.1109/PESGM.2012.6345652.

[39] B. Roossien, A. Van Den Noort, R. Kamphuis, F. Bliek, M. Eijgelaar, and J. De Wit, "Balancing wind power fluctuations with a domestic virtual power plant in Europe's first smart grid," 2011 IEEE PES Trondheim PowerTech Power Technol. a Sustain. Soc. POWERTECH 2011, pp. 1-5, 2011, doi: 10.1109/PTC.2011.6019158.

[40] K. Kok et al., "Agent-based electricity balancing with distributed energy resources, a multiperspective case study," Proc. Annu. Hawaii Int. Conf. Syst. Sci., 2008, doi: 10.1109/HICSS.2008.46.

[41] J. Bottieau, L. Hubert, Z. De Grève, F. Vallée, and J. F. Toubeau, "Very-Short-Term Probabilistic Forecasting for a Risk-Aware Participation in the Single Price Imbalance Settlement," IEEE Trans. Power Syst., vol. 35, no. 2, pp. 1218-1230, 2020, doi: 10.1109/TPWRS.2019.2940756.

[42] A. Essl, A. Ortner, R. Haas, and P. Hettegger, "Machine learning analysis for a flexibility energy approach towards renewable energy integration with dynamic forecasting of electricity balancing power," in International Conference on the European Energy Market, EEM, Jul. 2017, doi: 10.1109/EEM.2017.7981877.

[43] S. Jaehnert, H. Farahmand, and G. L. Doorman, "Modelling of prices using the volume in the Norwegian regulating power market," 2009 IEEE Bucharest PowerTech Innov. Ideas Towar. Electr. Grid Futur., vol. i, pp. 1-7, 2009, doi: 10.1109/PTC.2009.5281972.

[44] Ł. Mordasiewicz, "Price forecasting in the balancing mechanism," Rynek Energii, vol. 94, no. 3, 2011.

[45] EURELECTRIC, "Dynamic pricing in electricity supply," no. February, p. 16, 2017.

[46] T. Cui, Y. Wang, H. Goudarzi, S. Nazarian, and M. Pedram, "Profit maximization for utility companies in an oligopolistic energy market with dynamic prices," 2012 IEEE Online Conf. Green Commun. GreenCom 2012, vol. 4, no. December 2015, pp. 86-91, 2012, doi: 10.1109/GreenCom.2012.6519621.

[47] M. Vasirani and S. Ossowski, "Smart consumer load balancing: State of the art and an empirical evaluation in the Spanish electricity market," Artif. Intell. Rev., vol. 39, no. 1, pp. 81-95, 2013, doi: 10.1007/s10462012-9391-6.

[48] P. Vytelingum, T. D. Voice, S. D. Ramchurn, A. Rogers, and N. R. Jennings, "Agent-based micro-storage management for the smart grid," Proc. Int. Jt. Conf. Auton. Agents Multiagent Syst. AAMAS, vol. 1, no. Aamas, pp. 39-46, 2010.

[49] A. T. Radu, M. Eremia, and L. Toma, "Participation of the Electric Vehicles in the Balancing Market," 2019 Electr. Veh. Int. Conf. EV 2019, 2019, doi: 10.1109/EV.2019.8892975.

[50] C. Lewandowski, "An ICT Solution for Integration of Electric Vehicles in Grid Balancing Services," 2013 Int. Conf. Connect. Veh. Expo, 2013, doi: 10.1109/ICCVE.2013.110.

[51] P. Pinson, "Estimation of the uncertainty in wind power forecasting," Paristechbibrilkcom, p. 248, 2006, [Online]. Available: http://paristech.bib.rilk.com/2187/.

[52] P. Pinson, C. Chevallier, and G. N. Kariniotakis, "Trading wind generation from short-term probabilistic forecasts of wind power," IEEE Trans. Power Syst., vol. 22, no. 3, pp. 1148-1156, Aug. 2007, doi: 10.1109/TPWRS.2007.901117.

[53] H. Zareipour, C. A. Cañizares, and K. Bhattacharya, "Economic impact of electricity market price forecasting errors: A demand-dide analysis," IEEE Trans. Power Syst., vol. 25, no. 1, pp. 254-262, 2010, doi: 10.1109/TPWRS.2009.2030380.

[54] C. Monteiro, L. A. Fernandez-Jimenez, and I. Ramirez-Rosado, "Predictive Trading Strategy for Physical Electricity Futures," Energies, vol. 13, no. 14, p. 3555, 2020, doi: 10.3390/en13143555.

[55] A. H. Murphy, "What is a Good Forecast," June, 1993.

[56] C. Kath and F. Ziel, "The value of forecasts: Quantifying the economic gains of accurate quarter-hourly electricity price forecasts," Energy Econ., vol. 76, pp. 411-423, 2018, doi: 10.1016/j.eneco.2018.10.005.

[57] Á. Baldauf, "Trading Techniques for European Electricity Markets," 2018 . 